\title{
Waist to height ratio; a simple and valid index for metabolic syndrome in Korean adolescents
}

\author{
In-Hyuk Chung ${ }^{1 *}$, Sang Shin Park², Eun-Gyong Yoo ${ }^{1}$ \\ From 7th APPES Biennial Scientific Meeting \\ Nusa Dua, Bali. 14-17 November 2012
}

The incidence of metabolic syndrome (MS) is increasing in adolescents, which can lead to major health threats in the future. Body mass index (BMI) and waist circumference (WC) are commonly used for identifying adolescents at higher risk for MS, but BMI is not a measure of fat distribution, and different BMI and WC cut offs are used according to age. Waist-to-height ratio (WHtR) can be a good indicator for MS, because it includes WC, a good proxy for visceral adiposity. Same WHtR cut off might be used throughout adolescence because it accounts for growth in height by age. We evaluated the validity of WHtR, when compared to BMI and WC, in identifying adolescents with MS.

We analyzed data for 4,068 adolescents aged 10-18 years from the Korean National Health and Nutrition Examination Surveys conducted between 1998 and 2008. MS was defined by International Diabetes Federation criteria. The receiver operating characteristic (ROC) curve was used to determine the ideal WHtR cut off. Area under the curve (AUC), sensitivity and specificity of WHtR for identifying MS were calculated from the ROC curve, and compared with those of BMI ( $\geq 95 \mathrm{P}$ for age and sex) and WC ( $\geq 90 \mathrm{P}$ for age and sex).

The prevalence of MS was $2.4 \%$ in boys, $2.1 \%$ in girls. The ideal WHtR cut off was 0.51 (sensitivity $94.3 \%$, specificity $94.4 \%$ ) for boys, and 0.48 (sensitivity $100 \%$, specificity $87.6 \%$ ) for girls. In ROC curve analysis, the AUC of BMI, WC and WHtR were 0.957, 0.971 and 0.966 in identifying MS for boys and 0.935, 0.965 and 0.961 for girls, respectively. For boys, the sensitivity of BMI, WC and WHtR $(\geq 0.51)$ was65.4\%, $100 \%$ and $98.1 \%$ and specificity was $95.5 \%, 89.6 \%$ and $89.3 \%$, respectively. For girls, sensitivity of BMI, WC and WHtR $(\geq 0.48)$ was $67.5 \%$, $97.5 \%$ and $100 \%$ and specificity was $94.7 \%, 90.8 \%$ and

\footnotetext{
'Department of Pediatrics, College of Medicine, CHA University, Sungnam, Korea

Full list of author information is available at the end of the article
}

$87.8 \%$, respectively. WHtR is a simple and valid index for predicting MS in adolescents. WHtR is almost as useful as WC, and it has the advantage that age specific reference tables are not required.

\section{Authors' details \\ 'Department of Pediatrics, College of Medicine, CHA University, Sungnam, Korea. ${ }^{2}$ Department of Veterinary Integrative Biosciences, College of Veterinary Medicine and Biomedical Sciences, Texas A \& M University, College Station, TX, USA.}

Published: 3 October 2013

doi:10.1186/1687-9856-2013-S1-P171

Cite this article as: Chung et al:: Waist to height ratio; a simple and

valid index for metabolic syndrome in Korean adolescents. International Journal of Pediatric Endocrinology 2013 2013(Suppl 1):P171.
Submit your next manuscript to BioMed Central and take full advantage of:

- Convenient online submission

- Thorough peer review

- No space constraints or color figure charges

- Immediate publication on acceptance

- Inclusion in PubMed, CAS, Scopus and Google Scholar

- Research which is freely available for redistribution
() Biomed Central
C Biomed Central

(c) 2013 Chung et al; licensee BioMed Central Ltd. This is an Open Access article distributed under the terms of the Creative Commons Attribution License (http://creativecommons.org/licenses/by/2.0), which permits unrestricted use, distribution, and reproduction in any medium, provided the original work is properly cited. 